\title{
O "Anjo medroso" no acervo naïf do Museu de Arte Assis Chateaubriand (MAAC) em Campina Grande
}

\author{
Robson Xavier da Costa \\ Universidade Federal da Paraíba
}

\section{Resumo}

Este ensaio objetiva analisar a obra "Anjo medroso" do artista Alexandre Filho no acervo do Museu de Arte Assis Chateaubriand (MAAC), da cidade de Campina Grande, Paraíba, Brasil. O recorte Naïf do acervo do MACC é composto por 55 obras datadas de 1966 a 2004, contando com trabalhos de artistas significativos para a arte brasileira. Ao analisar a pintura trabalhei com a proposta da "leitura iconográfica" (PANOFSKY, 1991) aplicada a obra específica do artista, parti do pressuposto de que a produção Naïf é parte significativa da produção visual da arte brasileira, mantendo um nicho específico no Brasil e no mundo e que permanece como um campo aberto para o desenvolvimento de novas pesquisas na área.

Palavras chave: Arte Naïf. MAAC. Leitura de Imagens. Pesquisa. Alexandre Filho.

\section{Abstract}

This essay aims to analyze the piece "Fearful Angel" artist Alexandre Son in the Museum of Art Assis Chateaubriand (MAAC), the city of Campina Grande, Paraíba, Brazil. The clipping from the collection of Naïve MACC consists of 55 works dating from 1966 to 2004, with works of significant artists for Brazilian art. By analyzing the painting worked with the proposal of "iconographic reading" (Panofsky, 1991) applied to the specific work of the artist, broke the assumption that production is a significant part of Naïve visual production of Brazilian art, maintaining a specific niche in Brazil and in the world and remains as an open field for the development of new research in the area. Key Words: Naïve Art. MAAC. Reading Images. Search. Alexandre Filho. 


\section{Introdução}

O termo "Arte Naïf”, também denominado: arte "ínsita”, "primitiva”, "ingênua", "popular", "autodidata", "primária" e "tosca", expressões utilizadas como sinônimos, em textos de apresentação de catálogos de exposições e artigos sobre essa tipologia de arte, designa trabalhos produzidos por artistas (geralmente) autodidatas, difundidos a partir do final do Impressionismo na França por meio da obra de Henri Rousseau e também valorizado pelas primeiras vanguardas da arte moderna.

Comum no Brasil a partir do século XX, a produção de Arte Naïf foi se consolidando como uma referência constante do repertório visual brasileiro, diversos artistas destacam-se nesse campo, incluindo vários nordestinos. Após os anos 1960, foram criados museus, salões e galerias especializadas no país e no mundo. Com mercado garantido, apoiado por partidários entre os meios de comunicação, pela crítica especializada e acolhido pelas vanguardas, o artista Naïf virou sinônimo cult. A estética naïf é um exemplo claro de uma produção artística "entre culturas". Suas imagens, com cores fortes, formas distorcidas, figuras e cenários bucólicos, apontam aproximações formais com a arte popular, o artesanato e a arte infantil, embora seja essencialmente diferente delas.

A Arte Naïfé uma forma peculiar de representação de mundo, apresentando imagens com forte tendência expressiva ou lírica, fomentando um imaginário carnavalesco do mundo. Devido às cores e traços fortes, a pintura naïf aproxima-se de um padrão alegre e festivo, uma agressividade cromática que remete a paleta Fauvista, é o espaço da predominância do princípio do prazer visual.

Presente no acervo dos principais museus de arte moderna do país, as obras naïfs compõem um recorte particular dessas coleções. No acervo do MAAC - Museu de Arte Assis Chateaubriand, em Campina Grande, Paraíba; um dos três museus de arte criados por Assis Chateaubriand no Nordeste brasileiro na década de 1960; a coleção naïfé composta de 55 obras que compreendem um recorte temporal de 1966 a 2004.

$\mathrm{O}$ recorte naïf da coleção do MAAC em Campina Grande uma das mais importantes coleções públicas no Estado da Paraíba, conta com obras de artistas como José Antônio da Silva, Chico da Silva, Alexandre Filho, Elza Souza, Gerson de Souza, Grauben, Benita Figueiredo, Catanho, Clóvis Júnior, Cunha, Eunice Braz, Geraldo da Rocha, Gerson de Souza, Irene Medeiros, João Alves, José Lucena, Juca (Ovídio Melo), Manézinho Araújo, Manoel Faria Leal, Maria Lacerda, Miguel Guilherme dos Santos, Ninita, Paulo Pedro Leal, Peter Potock, entre outros, um panorama significativo da produção naïf no Brasil que foram mostradas ao público entre 18 de maio de 2010 e 19 de janeiro de 2011, na exposição de longa duração intitulada “A Paleta Naïf do MAAC", na sede do museu e da Fundação de Apoio ao Ensino, à Pesquisa e à Extensão (FURNE) - instituição que o administra.

Com essa exposição o público da Paraíba teve a oportunidade de ter contato com obras naïfs selecionadas pelo olhar atento da equipe de curadoria a partir da coleção do MAAC, que algum tempo não eram exibidas ao público. Essa foi uma oportunidade 
de enriquecer o repertório imagético e retomar a valorização de uma produção visual presente e constante no cenário das artes visuais da Paraíba, por meio do contato com a paleta naïf do MAAC.

\section{1. $0 \mathrm{MAAC}$ no cenário da arte paraibana}

Inaugurado em 20 de outubro de 1967 o Museu de Arte Assis Chateaubriand (MAAC), com sede em Campina Grande, Paraíba, fora do eixo Rio/São Paulo, em pleno coração do Nordeste do país, foi fruto da campanha de criação de museus regionais ${ }^{1}$ capitaneada pelo jornalista paraibano e magnata das comunicações, Assis Chateaubriand, natural da cidade de Umbuzeiro e criador do MASP, seu projeto era dotar as diversas regiões do país de museus de arte com acervos significativos para favorecer a democratização da arte em todo o território nacional.

O MAAC foi implantado em um prédio histórico onde funciona atualmente, na Av. Floriano Peixoto, 718, no Centro de Campina Grande, edifício construído para abrigar a primeira escola estadual de Campina, em 1924, o Grupo Escolar Sólon de Lucena, projeto do arquiteto italiano Hermenegildo di Lascio, radicado à época em João Pessoa, um edifício de influência eclética e neoclássica, sob a administração da Fundação Universidade Regional do Nordeste (FURNE). Em 1974 o museu foi transferido para o prédio que hoje abriga o Museu Histórico de Campina Grande. Em 1976, foi transferido para o prédio construído pela Prefeitura Municipal de Campina Grande, no Parque Evaldo Cruz, Largo do Açude Novo, um projeto de autoria de Renato Azevedo. A partir de 23 de dezembro de 1997, o MAAC, foi aos poucos transferido para o prédio original, com a restauração do mesmo e a reinauguração da Galeria de Arte. No $2^{\circ}$ semestre de 2007 procedeu-se à conclusão de seu retorno ao edifício do Grupo Escolar Sólon de Lucena, sob a direção da FURNE, agora chamada Fundação de Apoio ao Ensino, à Pesquisa e à Extensão.

A Universidade Estadual da Paraíba (UEPB), que surgiu com a estadualização da URNE (Universidade Regional do Nordeste), instituição que foi mantida pela FURNE, participou da direção do museu entre 1987 e 2007.

A coleção do MAAC teve início em 10 de agosto de 1967, quando o empresário da comunicação o jornalista Francisco de Assis Chateaubriand Bandeira de Melo, entregou ao Magnífico Reitor e Presidente da FURNE, o Prof. Dr. Edvaldo de Souza do Ó,

$\infty<\infty<\infty<\infty<\infty<\infty<\infty<\infty<\infty<\infty<\infty<\infty$

1 Assis Chateaubriand criou nos anos 1960 a Campanha Nacional de Museus Regionais para descentralizar o foco do eixo Rio-São Paulo da arte brasileira, criando três museus: o Museu de Arte de Feira de Santana (Bahia); o Museu de Arte Contemporânea de Olinda (Pernambuco) e o Museu Regional de Campina Grande (atual MAAC) e uma coleção que está sob a guarda do Museu Histórico e Artístico do Maranhão; o Museu Dona Beja em Araxá (Minas Gerais), a Galeria Brasiliana, em Belo Horizonte (Minas Gerais) e a Pinacoteca Rubem Berta em Porto Alegre (Rio Grande do Sul) a campanha teve apoio das empresas de aviação e radio comunicação, favorecendo a qualidade das coleções doadas. 
o primeiro acervo do museu, chamado "Coleção Assis Chateaubriand", com 120 peças, contendo obras de Pedro Américo, Cândido Portinari, Anita Malfatti, Ismael Nery, Antônio Dias, etc.

Atualmente, o acervo do MAAC é formado pelo registro de 566 peças entre pinturas, esculturas, desenhos, gravuras, colagens e técnicas mistas, de artistas locais, nacionais e internacionais, abrangendo um conjunto de obras representativas da arte brasileira, da "arte acadêmica a arte contemporânea". O MAAC desenvolve atividades de expografia, documentação e pesquisa museológica, ação educativa e cultural, biblioteca, arquivo institucional, oficina de conservação e restauro. Ao longo do tempo o acervo original foi sendo ampliado e ganhou obras significativas de brasileiros e estrangeiros.
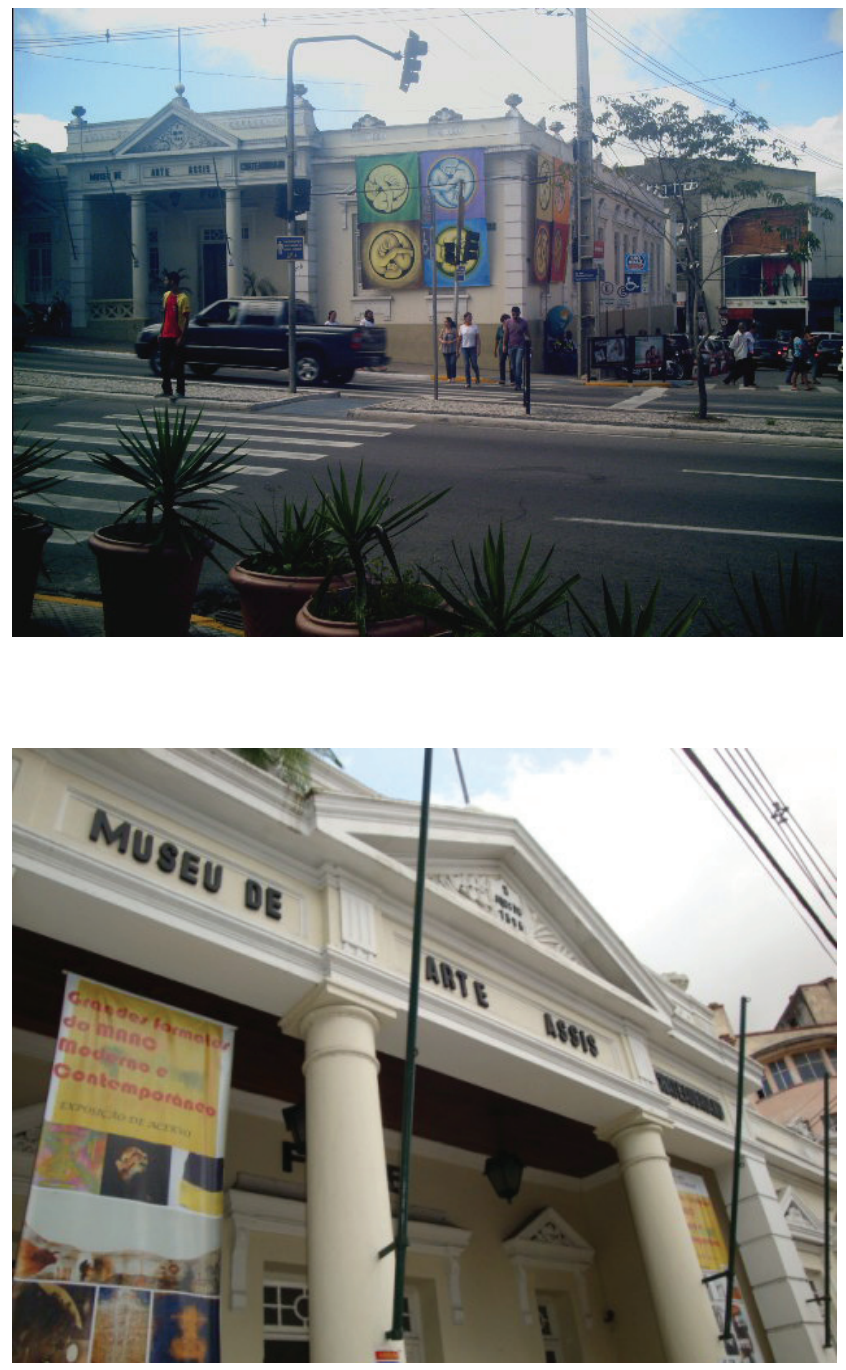

Figura 01

Fachada da atual Sede do MAAC. Foto disponível em: www.amarrandoentrelinhas. blogspot.com.

Figura 02

Fachada da atual Sede do MAAC. Foto disponível em: www.pm.pb.gov.br 


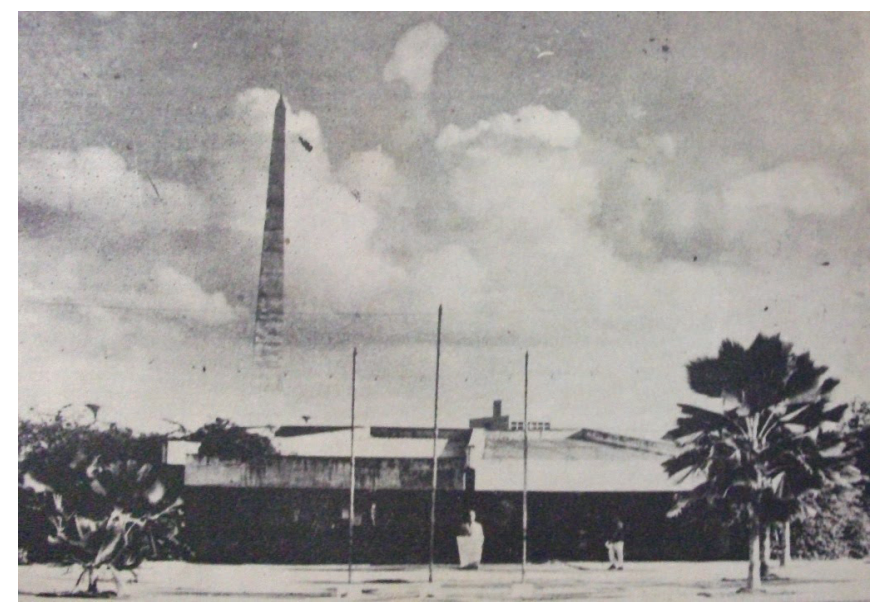

Figura 03

Fachada da antiga sede do MAAC

no Parque Evaldo Cruz (Açude

Novo). Foto disponível em:

www.cgretalhos.blogspot.com

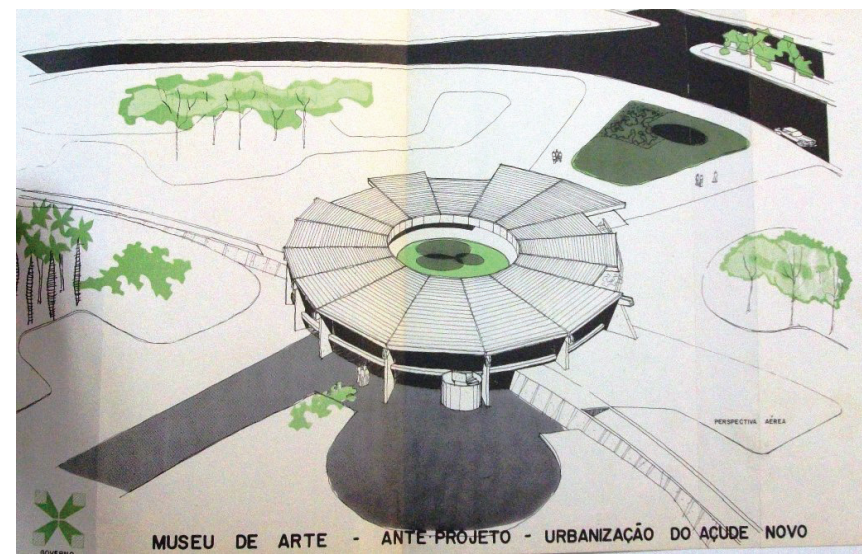

Figura 04

Projeto urbanização do Parque

Evaldo Cruz (Açude Novo) com

antiga sede do MAAC. Foto

disponível em:

www.cgretalhos.blogspot.com

No cenário museológico do Nordeste brasileiro e mais especificamente no contexto paraibano o MAAC simboliza a capacidade e importância da produção cultural da cidade de Campina Grande e região, no contexto das artes visuais brasileiras, origem de importantes artistas contemporâneos.

\section{2. "Anjo medroso" de Alexandre Filho no acervo de Arte naïf do MAAC}

Um anjo medroso é o título de um óleo sobre tela pertencente ao acervo do MAAC, doação do artista. Atualmente, a obra participa da exposição "Paraíba - uma Seleção", uma mostra do acervo na sede do MAAC. O tema no mínimo é ousado para o contexto da cultura nordestina, já que o anjo é um ícone ligado a enfrentamentos, lutas, coragem, religiosidade e força, o medo, não é, normalmente, um atributo associado ao ícone do anjo, mesmo o anjo menino (barroco), o artista inovou associando um 
sentimento humano a uma figura mitológica, tornando explicito no título da obra um sentimento considerado uma fraqueza para a cultura nordestina, afinal, como afirma o ditado popular "o nordestino é acima de tudo um forte".

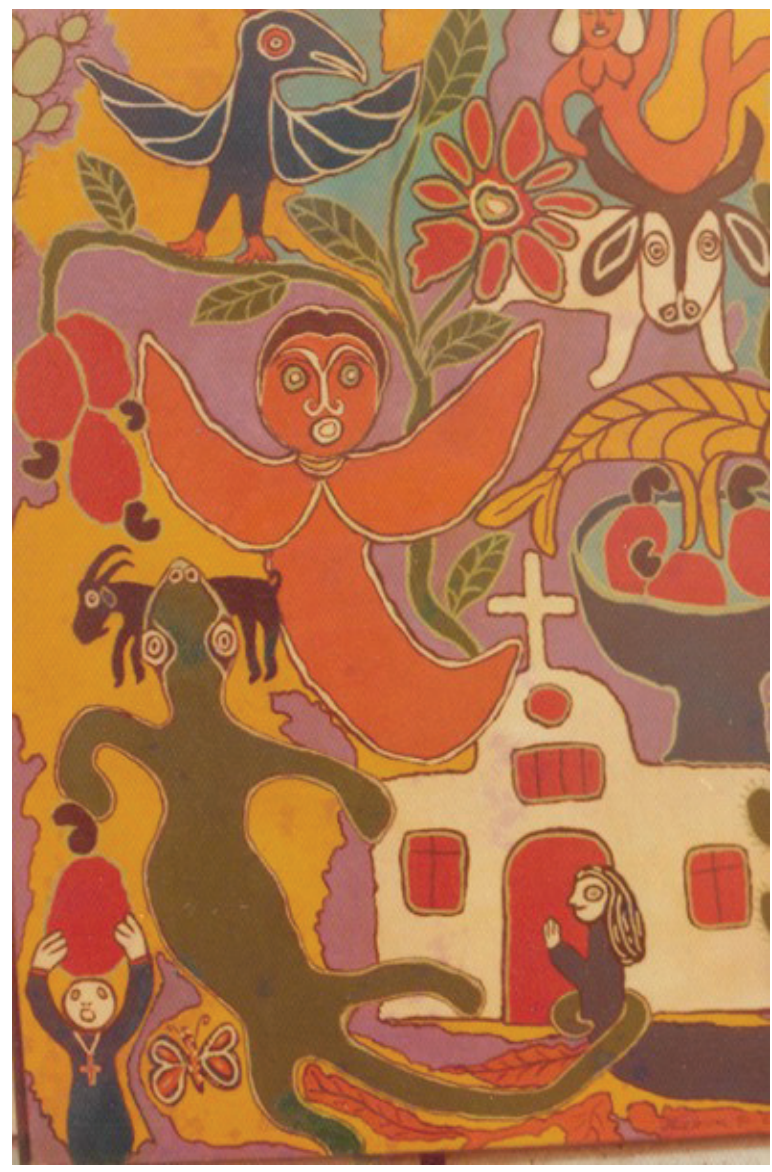

\section{Figura 05}

Alexandre Filho. "Anjo medro-

so". Acrílica sobre aglomerado.

$80,5 \times 60 \mathrm{~cm}$. 1966. Doado ao

MAAC em 1967 pelo artista.

Alexandre Filho nasceu na cidade de Bananeiras, no interior da Paraíba, em 1932. Morou durante alguns anos no Rio Grande do Norte, trabalhando como ajudante em um mercadinho; foi candango em Brasília, comerciário em Recife e no Rio de Janeiro, até o ano de 1966, pintou os primeiros trabalhos, estimulado por amigos e vizinhos, sendo selecionado com três telas para o XV Salão Nacional de Arte Moderna no Rio de Janeiro. A originalidade e a poética do seu trabalho encantaram o meio artístico do período, década de 1960. Alexandre já começou grande, expondo pela primeira vez em um dos mais importantes salões de arte do país. Seu sucesso foi meteórico; fixou ateliê no bairro de Santa Teresa, no Rio de Janeiro. Esse espaço tornou-se um ponto de encontro da boemia carioca da época, ajudando a consolidar a sua obra. Atualmente, Alexandre reside na cidade de João Pessoa, no bairro de Mangabeira I, onde continua desenvolvendo sua atividade artística. É considerado um dos mais importantes artistas Naïfs brasileiros vivos. 
Alexandre Filho apresenta-nos uma concepção de mundo onde a natureza é exuberante e divide de forma igualitária o espaço com as figuras humanas. Suas paisagens são quase surrealistas, criando figuras zoomorfas, flores, frutos e folhagens saídas do seu imaginário. Alexandre apresenta-nos uma forma de pintar a natureza diferenciada, pois as suas composições apresentam linhas contorcidas e as superfícies são contornadas por linhas sinuosas. Todo o imaginário naïf de Alexandre é transposto em puro movimento. Suas telas apresentam uma natureza exuberante, muitos tons de verde, flores coloridas e espaços bem delimitados; dos seus pincéis, surgem representações incomuns de uma flora vibrante, morada de animais estranhos e moldura para figuras humanas sensuais.

Seu imaginário figurativo apresenta seres mitológicos mesclados com personagens da cultura popular nordestina, inter-relacionando a religiosidade com as crenças mundanas do povo. Sua produção inicial (anos 1960) caracteriza-se pelo uso de superfícies de cores chapadas que definem as figuras coloridas delineadas por meio de um fino contorno preto, branco ou preto/branco, esse elemento define a forma das figuras, reforçando o desenho estabelecido pela superfície cromática, tornando a composição com forte movimento visual. Excelente colorista Alexandre Filho, foi pioneiro no uso de cores planas na pintura naïf brasileira e preserva na sua produção atual os traços originais que o definiram como um dos melhores artistas brasileiros naïfs de sua geração. A iconologia da sua obra rica em elementos marcantes da tradição cultural nordestina, símbolos como o caju, a sereia e animais míticos como o bode, o boi e o lagarto são elementos recorrentes.

$\mathrm{Na}$ obra de Alexandre, o anjo aparece como uma figura mitológica, inserida na representação de sua concepção religiosa, apreendida durante a infância: "talvez seja por conta da religiosidade da minha infância, frequentei muita igreja [...] talvez venha daí, não sei, pode ser, mas eu acho bonita a forma do anjo-criança, eu acho interessante criança" (ALEXANDRE FILHO, 2006). Como também representa o símbolo da pureza, o universo infantil, a liberdade, a brincadeira, o deslumbramento frente às agruras do mundo. Como observamos no quadro "o anjo medroso", a figura brinca integrada à natureza, interagindo com os animais: cabras, pássaros, peixes, bois. Uma infância revivida por meio da arte, como um sonho reconstruído pelos pincéis.

O anjo é uma imagem recorrente nas representações do imaginário católico colonial brasileiro. Quando jovem Alexandre conviveu, com igrejas barrocas e com figuras de anjos esculpidos na talha de jacarandá ou na pedra calcária; as figuras criadas pelo artista e o movimento visual da composição apresentam uma clara influência do imaginário barroco, com seus "anjinhos" gordinhos, asas pequenas, rostos rechonchudos, faces douradas e cabelos cacheados. 


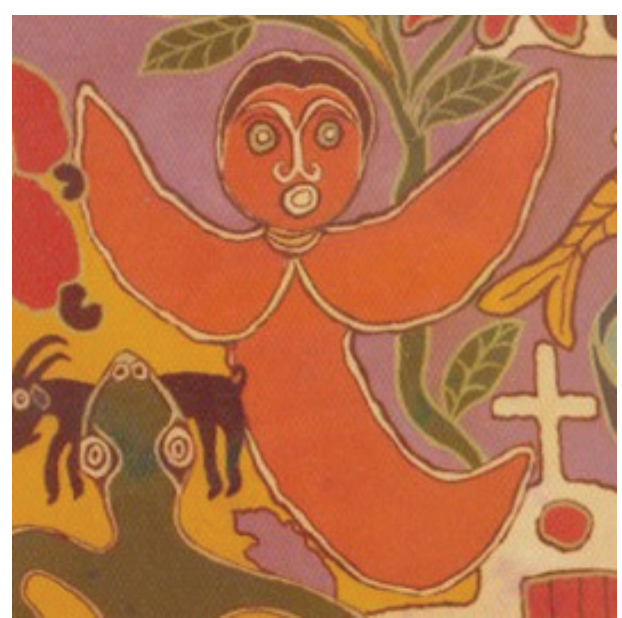

Figura 06

Alexandre Filho. "Anjo medroso". Detalhe do Anjo.

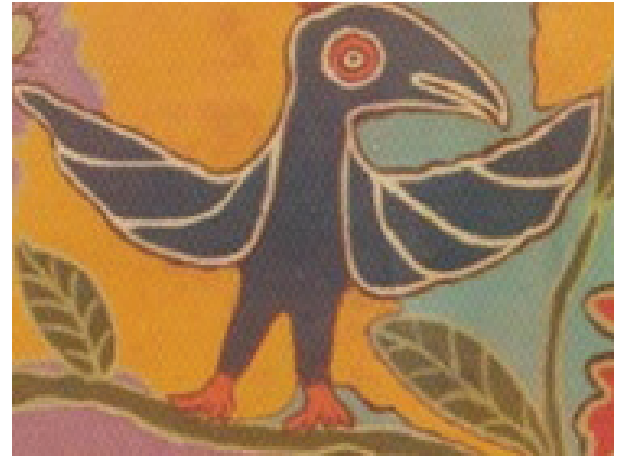

\section{Figura 07}

Alexandre Filho. "Anjo medroso". Detalhe do pássaro azul.

Na obra "Anjo medroso" (figura 05) os símbolos oníricos anjo (fig. 06), pássaros (fig. 07), boi, sereia, flor e folhas (fig. 10), igreja, padre, beata, borboleta, caju, bode e lagarto (figura 09), cajus, taça e peixe (figura 11), padre com caju (figura 08) figuras recorrentes no universo visual naïf de Alexandre Filho, são apresentadas juntas em um contexto de sonho, onde predomina a questão religiosa. A religião é apresentada de maneira irônica, a cena diante da igreja é incomum, o padre segura um grande caju no lugar da hóstia, a beata ajoelhada está presa ao rabo do lagarto e o cálice está cheio de cajus no lugar do vinho. A obra apresenta uma visão pessoal e sincrônica da religiosidade popular, ícones da religião católica substituídos por símbolos da cultura popular.

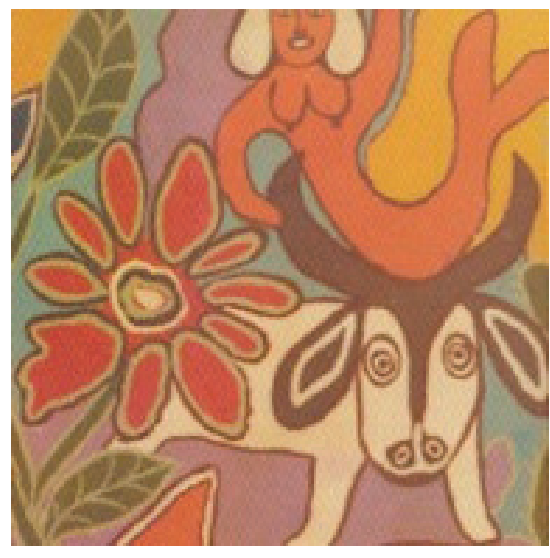

Figura 10

Alexandre Filho. "Anjo medroso". Detalhe flor, folhas, sereia e touro.

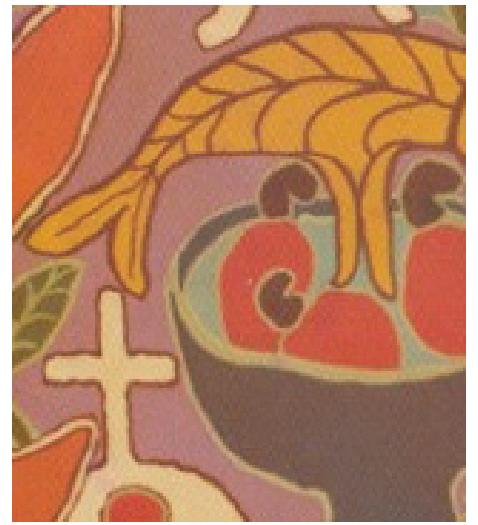

Figura 11

Alexandre Filho. "Anjo Medroso". Detalhe cajus, taça e peixe. 
Em termos formais a obra lembra o movimento visual dos trabalhos do artista russo Marc Chagall ${ }^{2}$ (1887 - 1985) (figura 12) e do artista moderno pernambucano Cícero Dias $^{3}$ (1907 - 2003) (figura 13) conhecido como o pequeno Chagall dos trópicos. Devido ao movimento intenso das figuras que parecem flutuar no espaço plano da composição, desconsiderando a gravidade.

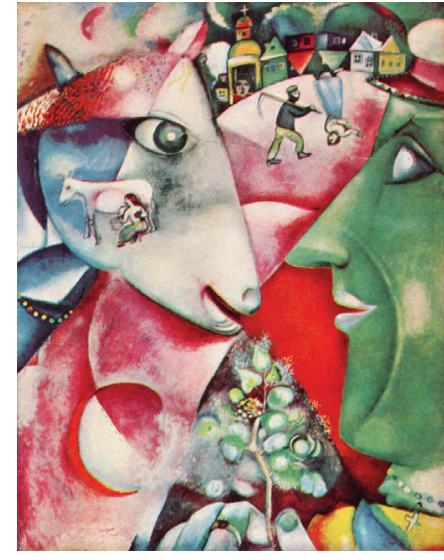

Figura 12

Marc Chagall. Eu e a aldeia. Óleo sobre tela. 1911. Museé National Marc Chagall. Foto disponível em: www.imaginariopoetico.com.br

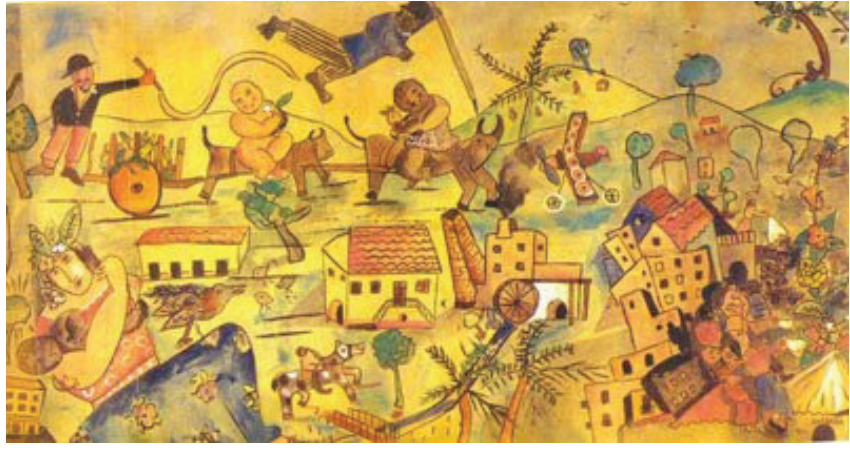

Figura 13

Cícero Dias. Eu vi o mundo... Ele começava no Recife. Detalhe. Painel em aquarela pintado em Papel Kraft. 13m x 2m. 1929. Foto disponível em: www.sinfoniapaulistana.blogspot.com

\section{Considerações finais}

O naïf, como signo estético, é um elemento de identidade, aberto permanentemente ao diálogo, à contaminação. Concordamos com Heller (1970, p.20), quando afirma que “a vida cotidiana não está 'fora’ da história, mas no 'centro' do acontecer histórico: é a verdadeira 'essência' da substância social”, o naïf parte do cotidiano do artista para tornar-se história.

$\infty<\infty<\infty<\infty<\infty<\infty<\infty<\infty<\infty<\infty<\infty<\infty$

2 Marc Chagall, artista surrealista judeu de origem russa, pintor, ceramista e gravurista. Sua obra foi fortemente marcada pela sua formação no ambiente rural da Rússia Czarista. Criou um mundo colorido e fantástico baseado nas suas memórias e vivências, morreu aos 97 anos, após uma vida de abundante produção artística.

3 Cícero Dias, artista ligado ao modernismo brasileiro, natural de Estrada, Pernambuco, morou a maior parte da vida em Paris, amigo dos artistas Pablo Picasso e Paul Éluard, desenvolveu boa parte de sua obra na França. 
Entendemos a estética naïf como uma história vista de baixo, com múltiplas incursões no cotidiano, no sagrado, no tellus, no lúdico dos artistas e de suas obras, situado como intérprete do seu tempo, dos grupos sociais aos quais se vincula e às suas comunidades de referência. Estudando esse universo, compreendemos o empoderamento que a arte possibilita aos artistas e ao seu contexto, permitindo a interculturalidade em meio à diversidade. A prática artística permite aos artistas significar e resignificar permanentemente suas experiências cotidianas, transformando memórias singulares em expressões artísticas compartilhadas coletivamente.

Além de possibilitar a perpetuação da trajetória individual do artista, a arte permite sua integridade, seu reconhecimento como cidadão, a construção de novas relações sociais e a permanência da sua forma de ser/pensar registrada por meio das imagens que cria. Nessa dimensão, considero que, através do trabalho artístico, o pintor naïf traduz o humano numa dimensão coletiva e popular, mesmo quando reafirma sua existência individual.

A arte naïf mantém-se como possibilidade de expressão para uma parcela significativa da comunidade de artistas. Trabalho ligado ao cotidiano popular, nessa iconografia, predominam as imagens do dia-a-dia, numa dimensão que a aproxima de um documento da vida cotidiana, em especial, das comunidades rurais e das pequenas cidades interioranas.

As obras naïfs convivem com a produção contemporânea na arte, possibilitando o questionamento dos códigos hegemônicos e etnocêntricos em vigor. Esse convívio foi derivado da abertura que deu origem à valorização da arte das "crianças", dos "esquizofrênicos", dos "selvagens" e dos "povos primitivos", produzidas em todo o mundo ocidental, com estruturas culturais diversas da instituída pelos códigos dominantes na arte.

Vinculando-se à tradição da cultura visual do povo, aceita pelos vanguardistas como forma de representação autêntica de uma cultura alheia à dominante ou como representação ingênua do mundo civilizado, a estética naïf mantém seu nicho produtivo em pleno auge da massificação das tecnologias. Compondo o acervo de museus, galerias e pinacotecas especializadas em todo o mundo e fazendo parte das principais coleções públicas e privadas, com um mercado garantido e uma produção constante, a arte naïf tem sido divulgada pelos mais variados meios de comunicação e valorizada por apresentar características regionais em meio à globalização da cultura, consolidando-se como um fenômeno da era contemporânea. 


\section{Referências bibliográficas}

A Paleta Naïf do MAAC. Campina Grande: Museu de Arte Assis Chateaubriand MAAC, Fundação de Apoio ao Ensino, Pesquisa e Extensão - FURNE, 18 maio 2010. Folder de exposição.

ARGAN, Giulio Carlo. Arte Moderna. Trad. Denise Bottman e Frederico Carotti. São Paulo:. Companhia das Letras, 2001.

COSTA, Robson Xavier da. Trajetórias do olhar: pintura naïf e história na arte paraibana. Dissertação de mestrado em História. João Pessoa, Paraíba, Brasil: UFPB - PPGH. 2007. Disponível em: http://www.dominiopublico.gov.br/pesquisa/DetalheObraForm. do?select_action=\&co_obra=93819. Acesso em: 24.06.2013.

. Texto de apresentação do folder da exposição "A paleta naïf do MAAC". Campina Grande: Museu de Arte Assis Chateaubriand - MAAC, Fundação de Apoio ao Ensino, Pesquisa e Extensão - FURNE, 2010.

FACEBOOK OFICIAL DO MAAC. https://www.facebook.com/MuseuDeArteAssis ChateaubriandMaac?fref=ts . Acesso em: 01.07.2013.

FILHO, Alexandre. Entrevista concedida a Robson Xavier da Costa. João Pessoa. 21 de março de 2006.

MAAC - SITE OFICIAL DA FURNE. http://www.fundacaofurne.org.br/portal/. Acesso em: 02.07.2013.

MANGUEL, Alberto. Lendo imagens: uma história de amor e ódio. Trad. Rubens Figueiredo, Rosaura Eichemberg e Cláudia Strauch. São Paulo: Cia das Letras, 2001.

MATERIAIS CONSULTADOS DO ACERVO DO MAAC: Imagens das obras naïs e suas referências.

PANOFSKY, Erwin. Significado nas artes visuais. Trad. J. Guinsburg e Maria Clara F. Kneese. São Paulo: Perspectiva, 1991.

SITE SOBRE IMAGENS DE CAMPINA GRANDE. http://www.marcusnogueira. com/2012/06/maac-museu-de-artes-assis-chateaubriand.html. Acesso em: 24.06.2013. 